\title{
Development and Validation of Stability indicating HPTLC Method for Estimation of Carbocisteine and Amoxicillin as Bulk Drug and in Drug Formulation by Derivatization
}

\author{
Kanchan Chauhan $^{1,2}$, Vishnu Choudhari ${ }^{2 \star}$ \\ 'Department of Pharmaceutical Chemistry, MCE Society's Allana College of Pharmacy, \\ Azam Campus, Camp, Pune-411001, India. \\ ${ }^{2}$ MAEER'S Maharashtra Institute of Pharmacy, MIT Campus, Paud Road, Kothrud \\ Pune-411038, India.
}

\begin{abstract}
A new, accurate, selective and sensitive stability indicating high performance thin layer chromatographic (HPTLC) method for simultaneous estimation of carbocisteine and amoxicillin was developed and validated. The compounds were well separated on aluminum plates precoated with silica gel $60 \mathrm{~F}_{254}$ using Butanol: Water: Ethanol: Acetic acid (5.5:1:2:1.5 $\mathrm{v} / \mathrm{v} / \mathrm{v} / \mathrm{v})$ as mobile phase. Developed plates were derivatized with ninhydrin reagent followed by heating at $110^{\circ} \mathrm{C}$ for $5 \mathrm{~min}$ in a preheated oven and scanned at $366 \mathrm{~nm}$. The retention factor for carbocisteine and amoxicillin were found to be 0.28 and 0.72 , respectively. Validation of the proposed method was carried out according to International Conference on Harmonization (ICH) guidelines. The current method demonstrates good linearity with correlation coefficients values 0.9996 and 0.9985 for carbocisteine and amoxicillin, respectively. The method was validated for precision, recovery and robustness and the values obtained were within ICH limits. The drugs were subjected to oxidation, acid and base hydrolysis, dry heat and UV light to apply stress condition for degradation studies as per ICH guidelines. The degradation products were well resolved from pure drug with different $R_{\mathrm{f}}$ values. Since the method effectively separates the drug from its degradation products it could be used as stability indicating method for analysis of individual drugs and the combined dosage form.

Keywords : Carbocisteine, Amoxicillin, stability indicating, HPTLC, Validation.
\end{abstract}

\section{Introduction}

Combination of drugs is widely used today due to their advantages. Their simultaneous estimation of individual component is a challenging task. The combination of Amoxicillin and Carbocisteine is emerging as one of the widely prescribed combination in single dosage form for the management of respiratory tract infections associated with excessive viscous mucus. Carbocisteine, a mucolytic agent, chemically is $(R)-2-$ Amino-3-(carboxymethylsulfanyl) propanoic acid[Fig.1A] with molecular formula $\mathrm{C}_{5} \mathrm{H}_{9} \mathrm{NO}_{4} \mathrm{~S}$ and molecular weight of 179.2 used in respiratory disorders associated with productive cough. 
Amoxicillin a $\beta$-lactum antibiotic, chemically is (2S, 5R, 6R)-6-[(2R)-2-amino-2(4 hydoxyphenyl) acetyl] amino]-3, 3-dimethyl-7-oxo-4-thia-1-azabicyclo heptane-2-carboxylic acid [Fig.1B] with molecular formula of $\mathrm{C}_{16} \mathrm{H}_{19} \mathrm{~N}_{3} \mathrm{O}_{5} \mathrm{~S}$, and molecular weight of 365.404. It is highly active against broad spectrum of bacteria used for the treatment of respiratory tract infections.

Literature survey reveals that several methods are reported based on HPLC chromatographic assay, bioanalytical assay, stability assay methods and UV Spectrophotometric methods for Amoxicillin ${ }^{1-5}$ and HPLC methodreportedforCarbocisteine ${ }^{6}$ for their individual estimation. Various HPLC and UV spectrophotometric methods are also reported for estimation of the titled analytes in combination with other drugs ${ }^{7-15}$. HPLC and derivative UV spectrophotometric methods are reported for determination of amoxicillin and carbocisteine in combination ${ }^{16-17}$. Literature survey also indicate that there is no stability indicating method available for estimation of the titled analytes; whereas stability indicating method is required for stability studies as per ICH guidelines ${ }^{18-21}$.Recently, HPTLC offer several advantages and currently it is widely employed for the identification and quantification of pharmaceuticals. Advantages offered by HPTLC include short analysis time, parallel processing of samples, low maintenance cost, low mobile phase consumption per sample, multiple or repeated scanning of chromatograms, no prior treatment for solvents and minimum sample solution consumption. Moreover, it is modular system and flexible enough to analyze different kinds of samples by different analyst. ${ }^{22-23}$ Currently HPTLC testsare included in pharmacopoeia due to its high sensitivity and its utility; thus the applications of HPTLC technique are getting wide acceptance. ${ }^{24}$ Therefore the aim of the current study was to develop anovel, simple, precise and reproducible HPTLC method with forced degradation studies for simultaneous estimation of carbocisteine and amoxicillin from its formulation.

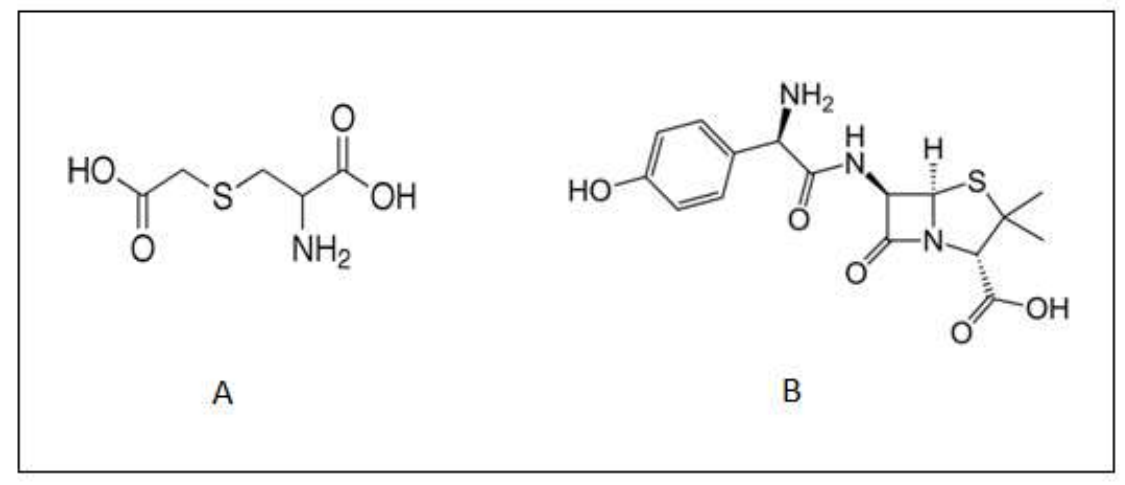

Figure.1:Structure of Drugs, A-carbocisteine and B-amoxicillin

\section{Experimental}

\section{Solvents and chemicals}

Standard drug carbocisteine was purchased from Swapanaroop Drugs and Chemicals, Aurangabad and Amoxicillin was supplied as gift sample by Elder Pharmaceuticals Pvt. Ltd., Mumbai. All other chemicals such as butanol, ethanol, acetic acid used in the study were of analytical grade and purchased from Merck Pvt. Ltd. The pharmaceutical dosage form used in this study was fixed dose combination Mucobron Capsules (Elder Pharmaceuticals Ltd.) each containing carbocisteine $150 \mathrm{mg}$ and amoxicillin trihydrate $250 \mathrm{mg}$ was procured from local market.

\section{HPTLC Instrumentation and optimization of chromatographic conditions}

The sample solutions were applied on pre-washed and activated precoated silica gel aluminium HPTLC plate $60 \mathrm{~F}_{254}(20 \mathrm{~cm} \times 10 \mathrm{~cm}$ with $250 \mu \mathrm{m}$ thickness; E. Merck, Darmstadt, Germany $)$ in the form of bands of 6 mm width with a Hamilton syringe $(100 \mu \mathrm{l})$ using a Camag Linomat V (Switzerland) sample applicator. The slit dimension was kept at $5 \mathrm{~mm} \times 0.45 \mathrm{~mm}$ and $10 \mathrm{~mm} / \mathrm{s}$ scanning speed was employed. HPTLC plate was then developed, with20 $\mathrm{ml}$ mobile phase consisting of Butanol: Water: Ethanol: Acetic acid (5.5:1:2:1.5 $\mathrm{v} / \mathrm{v} / \mathrm{v} / \mathrm{v}$ ). Linear ascending development was carried out in $20 \mathrm{~cm} \times 10 \mathrm{~cm}$ twin trough glass chamber (Camag, Muttenz, Switzerland) saturated with the mobile phase. The chamber saturation time for mobile phase was 25 
min at room temperature. Densitometric scanning was performed using Camag TLC scanner III with winCATS software version 1.4.4 in the reflectance mode at $366 \mathrm{~nm}$.

\section{Derivatization method and detection wavelength}

After chromatographic development the plate was dried under air current and ninhydrin reagent as a derivatizing agent was sprayed on the plate by using sprayer. The plate was then heated at $110^{\circ} \mathrm{C}$ for 5 min in a pre-heated oven. Densitometric scanning was performed within $20 \mathrm{~min}$ after derivatization process and the bands were scanned over the range of 200-600 nm with as can speed of $10 \mathrm{~mm} / \mathrm{s}$. It was observed that both drugs showed absorbance at $366 \mathrm{~nm}$ and hence same wavelength was selected for analysis of both compounds.

\section{Preparation of standard stock solutions}

Standard stock solutions of pure compounds were prepared separately by dissolving 100mg each of carbocisteine and amoxicillin in $100 \mathrm{ml} 0.01 \mathrm{~N} \mathrm{HCl}$ to get concentration of $1000 \mu \mathrm{g} / \mathrm{ml}$. These stock solutions were sonicated for $15 \mathrm{~min}$ and used for further studies. A series of solutions containing mixture of drugs were prepared by transferring appropriate aliquots from standard stock solutions and diluting to volume with methanol. Five working standard stock solutions containing carbocisteine and amoxicillinfrom50 - 500 and 80$800 \mu \mathrm{g} / \mathrm{ml}$, respectively were prepared. The concentrations were fixed, taking into account the proportion in which carbocisteine and amoxicillin are present in capsule formulation.

\section{Preparation of sample solutions}

Twenty capsules were weighed and average weight was determined. An accurately weighed powder sample equivalent to $15 \mathrm{mg}$ of carbocisteine $(25 \mathrm{mg}$ of amoxicillin)was transferred to a $100 \mathrm{ml}$ volumetric flask containing $50 \mathrm{ml}$ of $0.01 \mathrm{~N} \mathrm{HCl}$, the flask was sonicated for about $20 \mathrm{~min}$ and the volume was made with $0.01 \mathrm{~N}$ $\mathrm{HCl}$; resultant solution was filtered through Whatman filter paper no 41. Working sample solutions were freshly prepared by diluting suitable volumes of the sample stock solution with methanol.

\section{Method Validation}

The developed method was validated as per the International Conference on Harmonization (ICH) guidelines ${ }^{21}$ by evaluating linearity, accuracy, precision, robustness, detection limit, quantification limit and specificity.

\section{Linearity}

The aliquots of standard mixtures were spotted on a TLC plate and were evaluated in the range of 50$500 \mathrm{ng} / \mathrm{spot}$ for carbocisteine and80-800 ng/spot for amoxicillin. The analytes were resolved under optimized chromatographic conditions. Peak area versus concentration was subjected to least square linear regression analysis and the intercept, slope and correlation coefficient for the calibration were determined. The whole procedure was repeated thrice starting from weighing of analytes to preparation of the standard solution. A good linear relationship between response (peak area) and concentration was obtained. Also, the residual plots of relative response against concentration were plotted, and observed for trending.

\section{Limit of Detection (LOD) and limit of Quantification (LOQ)}

The limits of detection and limits of quantification of the developed method were calculated using regression equation. It was calculated from the standard deviation of the y-intercepts and slope of the calibration curves of carbocisteine and amoxicillin using the formulae as LOD $=3.3 \mathrm{x} \sigma / \mathrm{S}$ and $\mathrm{LOQ}=10 \mathrm{x} \sigma / \mathrm{S}$, where $\sigma$ is standard deviation and $\mathrm{S}$ is slope of calibration plot.

\section{Precision studies}

For the precision both repeatability and intermediate precision of the method for drug was checked. For repeatability the peak area of sample band was measured repeatedly $(n=6)$ and the $\%$ relative standard deviation (\% RSD) was calculated. For intradayprecision, the peak area of sample at three different concentrations (100, 200 and 400ng/spot, and 160, 320, $640 \mathrm{ng} / \mathrm{spot}$ for carbocisteine and amoxicillin, respectively) were measured for three times $(n=3)$ on the same day. For interday precision same concentrations were applied on plate; plate 
developed, derivatized and scanned on three different days and the \% relative standard deviation (\% RSD) was calculated.

\section{Recovery studies}

The recovery studies were performed by spiking three different known quantity of pure standard drug into the sample solution. The sample was spiked with standard at levels $80 \%, 100 \%$ and $120 \%$ of test concentration. The quantities of formulation used for spiking at three levels were $150 \mathrm{ng} / \mathrm{band}$ for carbocisteine and 250ng/band for amoxicillin. The resulting spiked sample solutions were assayed in triplicate and the results were compared with the expected results; \% RSD (relative standard deviation) and the mean recovery were calculated.

\section{Assay:}

The drug content obtained from standard and the sample was found to be comparable with no interference from the excipients commonly present. For the study 20 capsules were weighed and average weight was calculated. An accurately weighed powder sample equivalent to $15 \mathrm{mg}$ of carbocisteine $(25 \mathrm{mg}$ of amoxicillin) was transferred to a $100 \mathrm{ml}$ volumetric flask and volume was made up to $100 \mathrm{ml}$ with $0.01 \mathrm{~N} \mathrm{HCl}$. The solution was sonicated for about 20 min and the volume was made with $0.01 \mathrm{~N} \mathrm{HCl}$. The resultant solution was filtered through Whatman filterpaper no. 41. Working sample solutions were prepared by diluting suitable volumes of the sample stock solution with methanol. The resultant solutions were applied to the HPTLC plate; plate was derivatized and scanned at $366 \mathrm{~nm}$.

\section{Robustness studies}

The effect of small, deliberate variation of the analytical conditions on the peak areas and retention factor of the analytes were examined. The HPTLC method parameters like small change in mobile phase composition $( \pm 0.1 \mathrm{ml})$, amount of mobile phase $( \pm 5 \%)$, chamber saturation $( \pm 5 \mathrm{~min})$, time from spotting to chromatography $( \pm 10 \mathrm{~min})$, time from chromatography to derivatisation $( \pm 5 \mathrm{~min})$ and time from derivatisation to scanning ( $\pm 5 \mathrm{~min}$ )were studied. The effect of these changes on both the $\mathrm{R}_{\mathrm{f}}$ values and peak areas were studied by calculating\% RSD for each parameter. Robustness of the method was evaluated at concentration level of 150ng/band and 250ng/spot for carbocisteine and amoxicillin, respectively.

\section{Specificity}

The specificity of the developed method was established by analyzing the sample solutions containing carbocisteine and amoxicillin in formulation and observed for any unresolved excipient peaks as well as for any coelution with analyte peaks. The $\mathrm{R}_{\mathrm{f}}$ values of carbocisteine and amoxicillin in the sample was confirmed by comparing it with standard spots.Stress degraded samples of carbocisteine and amoxicillin using different stress conditions were analysed to check separation of analyte peak form stress degraded peaks and any coelution of degraded peak with analyte peak.

\section{Band Stability}

The time when the sample is left to stand on plate prior to chromatographic development can influence the stability of separated spots and are required to be investigated for validation. Two-dimensional chromatography using the same solvent system was used to find out any decomposition occurring during spotting and development.

\section{Colour stability:}

The time the plate is left to stand after derivatization can influence the colour stability of the analyte bands and are required to be investigated. Bands were scanned at different time interval after derivatization and area of band recorded for 5, 10, 20, 30 and $60 \mathrm{~min}$ and \% RSD was calculated.

\section{Solution (Method) stability:}

Stability of solution was studied after $0,1,2,4$ and 6hours storage at room temperature. The solutions were applied on TLC plate, plate were derivatized and scanned at $366 \mathrm{~nm}$. The stability of the solutions was 
determined by comparing peak areas of the developed band at each time point against freshly prepared standard solution and the percentage relative standard deviation was calculated.

\section{Forced degradation study}

The study was intended to ensure the effective separation of carbocisteine and amoxicillin and their degradation peaks. Forced degradation studies were performed to evaluate the stability indicating properties and specificity of the method. The objective of stress study was to generate the degradation products under various stress conditions and to verify that the degradation peaks are well resolved from the main peaks by developed method. ${ }^{18-20}$ The stress conditions employed for degradation study include acid hydrolysis $(0.1 \mathrm{~N} \mathrm{HCl})$, base hydrolysis $(0.1 \mathrm{~N} \mathrm{NaOH})$, peroxide oxidation $\left(3 \% \mathrm{H}_{2} \mathrm{O}_{2}\right)$, thermal and photolytic degradation. The stock solutions were prepared separately which contains $100 \mu \mathrm{g} / \mathrm{ml}$ of carbocisteine and amoxicillin each. These solutions were subjected to stress degradation as per the procedures described below. The resulting solutions were applied on TLC plates and the chromatograms were run under the conditions described above. The stress degradation studies were performed on the bulk drugs separately and in combination.

\section{Acid and base degradation}

Studies were carried out by taking $2 \mathrm{ml}$ of working solution (in a 10ml standard volumetric flask) and mixing it with $2 \mathrm{ml}$ of $0.1 \mathrm{~N} \mathrm{HCl} / 0.1 \mathrm{~N} \mathrm{NaOH}$. These solutions were allowed to stand for 4 hours at room temperature. Both the samples were neutralized and diluted up to $10 \mathrm{ml}$. The resultant solutions were applied on TLC plate and scanned at $366 \mathrm{~nm}$. The chromatograms were recorded to assess the stability of the sample.

\section{Oxidation}

To $2 \mathrm{ml}$ of working standard solution $2 \mathrm{ml}$ of $3 \% \mathrm{v} / \mathrm{v}$ of hydrogen peroxide was added and allowed to stand for 4 hours at room temperature. The resultant solution was suitably diluted and applied on TLC plate.

\section{Thermal Degradation}

Stress testing under neutral conditions was studied by refluxing $2 \mathrm{ml}$ of stock solution in water for 4hours at a temperature of $60^{\circ} \mathrm{C}$. The resultant solution was suitably diluted and applied on TLC plate.

\section{Dry Heat Degradation}

For dry heat degradation $50 \mathrm{mg}$ of samples transferred to petri plate and was exposed to dry heat at $80^{\circ}$ $\mathrm{C}$ for 4 hours. The resultant solution was suitably diluted and applied on TLC plate.

The samples exposed to acid, base, oxidation, thermal and dry heat degradation study were applied as band on TLC plates, plates were developed, derivatized and scanned at $366 \mathrm{~nm}$ for the determination of $\%$ of analyte degradation, $\mathrm{R}_{\mathrm{f}}$ values of the analyte and degraded products.

\section{Results and Discussion}

\section{HPTLC method optimization}

Based on literature survey initially various mobile phases containing different ratios of acetone, nhexane, ethanol, methanol, toluene, ethyl acetate, acetone and water were tried which gives poorly resolved peaks with tailing and fronting. Butanol: Water: Ethanol $(6.5: 1: 2.5 \mathrm{v} / \mathrm{v} / \mathrm{v} / \mathrm{v})$ was selected as mobile phase. In this mobile phase peaks were well resolved but with unacceptable tailing and fronting of all peaks. Various trials were carried out by changing the composition of the solvents used; acetic acid was used to improve tailing and fronting. Finally, the mobile phase consisting of Butanol: Water: Ethanol: Acetic acid (5.5:1:2:1.5 v/v/v/v) was selected which gave well resolved peaks without tailing and fronting. Necklace effect during plate development was reduced by saturating TLC chamber for 25 min using saturation pads. Separated compounds are colorless, do not respond to UV radiation, and do not fluoresce; hence derivatization is used to enhance detection in which suitable reagent is applied to the TLC plate, which reacts with the sample compounds and transforms them into detectable derivatives. Several derivatizing agents have been tried such as $10 \%$ sulphuric acid, anisaldehyde, 5\% sulphuric acid and ninhydrin reagent. Ninhydrin reagent showed promising and 
reproducible results with chromophore stability more than 8hour and hence was selected for derivatization. It was prepared by dissolving $0.2 \mathrm{gm}$ ninhydrin in ethanol in $100 \mathrm{ml}$ volumetric flask and final volume was adjusted with ethanol.

After chromatography, developed plate was dried and ninhydrin solution was sprayed on the plate and heated at $110^{\circ} \mathrm{C}$ for $05 \mathrm{~min}$ in a pre-heated oven. Densitometric scanning was performed within 10 min after derivatization process using Camag TLC scanner III with winCATS software version 1.4.4.Thebands were scanned over the range of $200-600 \mathrm{~nm}$ with scan speed of $10 \mathrm{~mm} / \mathrm{s}$. It was observed that both drugs showed absorbance at $366 \mathrm{~nm}$ and hence was selected for analysis of compounds. The retention factors for carbocisteine and amoxicillin were found to be 0.28 and 0.72 , respectively after derivatization [Fig.2].

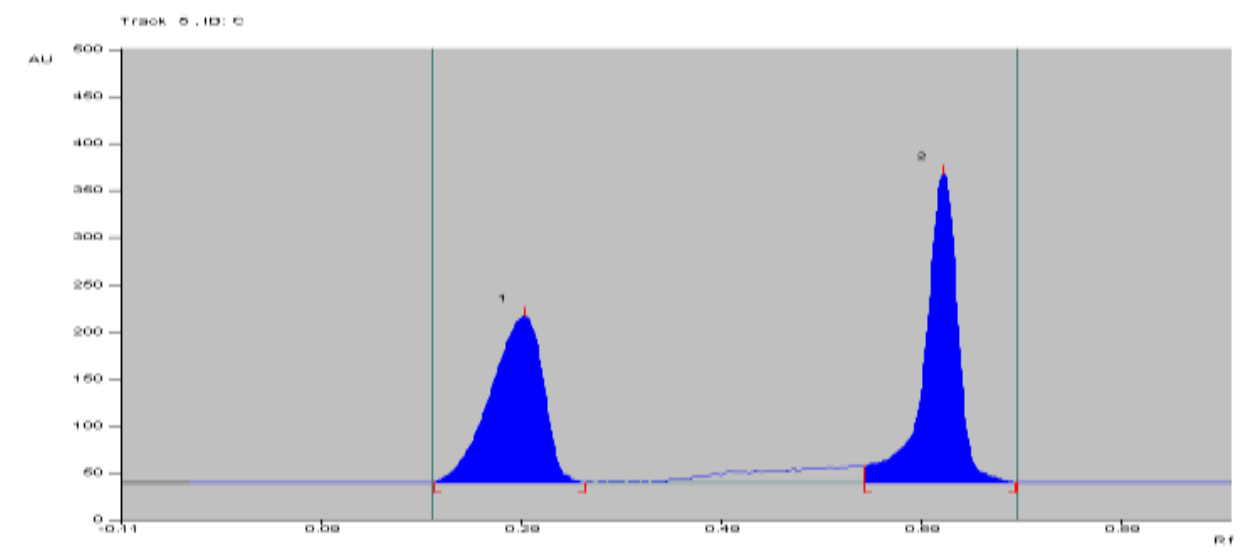

Figure 2: Chromatogram of carbocisteine and amoxicillin after derivetization with ninhydrin reagent. Peak 1carbocisteine: $R_{\mathrm{f}}: 0.28$, Peak 2: amoxicillin $R_{\mathrm{f}}: 0.72$ at $366 \mathrm{~nm}$

\section{HPTLC method validation}

\section{Linearity, limit of detection and limit of quantitation}

Calibration curves were obtained for carbocisteine and amoxicillin from which linear regression equation was computed and a correlation coefficient was obtained. Linear regression data for the calibration plots $(\mathrm{n}=3)$ are listed in [Table 1]. The results were found to be linear in the range of $50-500 \mathrm{ng} / \mathrm{spot}$ for carbocisteine and 80-800ng/spot for amoxicillin. The correlation coefficients values were 0.9996 and 0.9985 for carbocisteine and amoxicillin, respectively which shows excellent linearity between the concentration of analytes and chromatographic response. From the above data, values of standard deviation and the slope were calculated for both analytes. Further method sensitivity was determined form the calculated values of LOD and LOQ by using LOD and LOQ equation as mentioned in procedure section. The LOD and LOQ values were found to be 17.5, 53ng/spot for carbocisteine and 42.56, 128.9ng/spot for amoxicillin, respectively. To further confirm linearity, F test was applied where the value of experimental Fischer ratio was compared against the critical value found in statistical tables for both analytes; experimental $\mathrm{F}$ ratio values were found to be less than the tabulated value at the $95 \%$ confidence level. Furthermore the residual plots of relative response against concentration were plotted for carbocisteine and amoxicillin as presented in Fig.3 and Fig.4, respectively; residual plots show no trending.

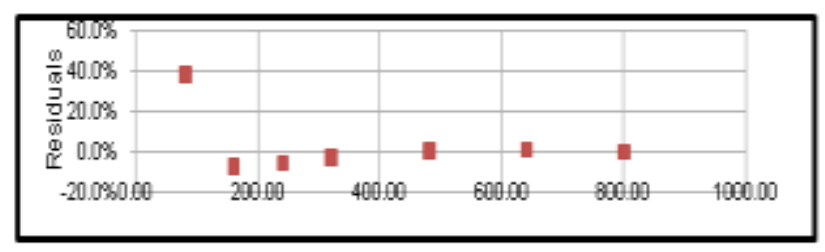

Figure 3 Residual plot of carbocisteine

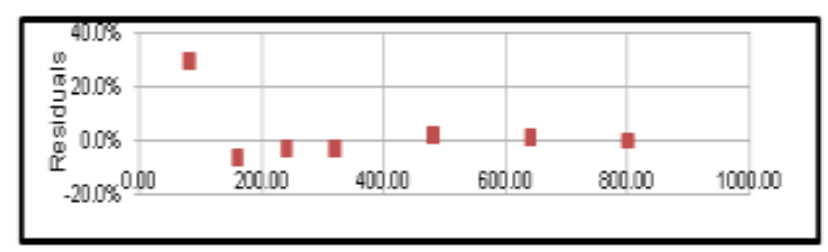

Figure 4 Residual plot of amoxicillin 
Table1: Summary of linear regression and method sensitivity study

\begin{tabular}{|l|l|l|}
\hline Parameter & Carbocisteine & Amoxicillin \\
\hline Linearity Range & $50-500 \mathrm{ng} / \mathrm{spot}$ & $80-800 \mathrm{ng} / \mathrm{spot}$ \\
\hline Linear regression equation & $\mathrm{y}=9.472 \mathrm{x}+45.72$ & $\mathrm{y}=20.34 \mathrm{x}+482.7$ \\
\hline Slope & 9.472 & 20.34 \\
\hline Intercept & 45.72 & 482.7 \\
\hline Correlation coefficient & 0.9996 & 0.9985 \\
\hline Limit of detection (LOD) & 17.49 & 42.56 \\
\hline $\begin{array}{l}\text { Limit of quantitation } \\
\text { (LOQ) }\end{array}$ & 53 & 128.99 \\
\hline
\end{tabular}

\section{Precision}

Precision of the method was determined by repeatability and intermediate precision. It was expressed in terms of relative standard deviation (\%RSD) of the peak area. Study shows that the repeatability, intra- and inter-day variation of the results for carbocisteine and amoxicillin were within the acceptable range. The coefficients of variation for both the inter-day and intraday precision of the method was found to be less than 1 for both drugs indicating a good precision. The summary of intermediate precision study is presented in Table 2 .

Table 2: Results of the precision $\operatorname{study}(n=3)$

\begin{tabular}{|l|l|l|l|l|l|l|}
\hline Drug & \multicolumn{3}{|l|}{ Carbocisteine } & \multicolumn{3}{l|}{ Amoxicillin } \\
\hline Concentration (ng/band) & 100 & 200 & 400 & 160 & 320 & 640 \\
\hline Intraday (\% RSD) & 0.30 & 0.38 & 0.19 & 0.80 & 0.95 & 0.51 \\
\hline Inter day (\% RSD) & 0.46 & 0.15 & 0.20 & 0.93 & 0.63 & 0.46 \\
\hline
\end{tabular}

\section{Accuracy}

The recovery studies were carried out at $80 \%, 100 \%$ and $120 \%$ of the test concentration as per ICH guidelines. The percentage recovery of carbocisteine and amoxicillin at all the three levels was found to be satisfactory. For carbocisteine the \% recovery was found in the range of $99.53 \%-100.34 \%$ and for amoxicillin between $98.84 \%-100.05 \%$, respectively. [Table 3]

Table3: Recovery studies $(n=6)$

\begin{tabular}{|l|l|l|l|l|l|}
\hline Drug & \multirow{2}{*}{$\begin{array}{l}\text { Recovery } \\
\text { level }(\boldsymbol{\%})\end{array}$} & \multicolumn{2}{|l|}{ Amount (ng/band) } & \% Recovery & \multirow{2}{*}{ \% RSD } \\
\cline { 2 - 4 } & 80 & 150 & 120 & 99.53 & \\
\hline \multirow{3}{*}{ Carbocisteine } & 80 & 150 & 150 & 100.34 & 0.86 \\
\cline { 2 - 6 } & 100 & 150 & 180 & 99.81 & 0.53 \\
\cline { 2 - 6 } & 120 & 250 & 200 & 98.84 & 0.69 \\
\hline \multirow{3}{*}{ Amoxicillin } & 80 & 250 & 250 & 98.91 & 0.84 \\
\cline { 2 - 4 } & 100 & 250 & 300 & 100.05 & 0.46 \\
\cline { 2 - 4 } & 120 & & & & 0.68 \\
\hline
\end{tabular}

\section{Analysis of marketed formulation}

The drug content in the marketed formulation was found to be $100.48 \%$ and $100.10 \%$ carbocisteine and amoxicillin, respectively. There was no interference of the excipients present in the marketed formulations and the low \% RSD value indicated the suitability of this method for routine analysis of carbocisteine and amoxicillin in pharmaceutical dosage form. [Table 4] 
Table 4: Assay results of the pharmaceutical dosage form $(n=6)$

\begin{tabular}{|l|l|l|}
\hline $\begin{array}{l}\text { Amount of drug present } \\
\text { (mg per capsule) }\end{array}$ & \% Assay & \% RSD \\
\hline Carbocisteine $150 \mathrm{mg}$ & 100.48 & 0.603 \\
\hline Amoxicillin $250 \mathrm{mg}$ & 100.10 & 0.368 \\
\hline
\end{tabular}

\section{Robustness studies}

Robustness of the proposed method was evaluated by deliberate alterations of the analytical parameters indicated that areas of peaks of interest and retention factor remained unaffected by small changes of the operational parameters. Percentage (\%) RSD of the test results of the selected parameters at different condition was calculated and found within the ICH limit (\% RSDNMT 2\%), indicating that the method is sufficiently robust to analyze carbocisteine and amoxicillin in pharmaceutical dosage form. [Table 5]

Table 5: Results of robustness study

\begin{tabular}{|l|l|l|l|l|}
\hline \multirow{2}{*}{ Parameter } & \multicolumn{2}{|l|}{ Carbocisteine } & \multicolumn{2}{l|}{ Amoxicillin } \\
\cline { 2 - 5 } & $\begin{array}{l}\text { \% Assay, } \\
\text { \% RSD }\end{array}$ & R fvalue & $\begin{array}{l}\text { \% Assay, } \\
\text { \% RSD }\end{array}$ & $\mathbf{R}_{\mathbf{f}}$ value \\
\hline Volume of mobile phase $( \pm 1 \mathrm{ml})$ & $100.45,0.87$ & 0.29 & $99.67,1.06$ & 0.71 \\
\hline Time of saturation $( \pm 5 \mathrm{~min})$ & $100.6,0.97$ & 0.28 & $100.3,0.97$ & 0.72 \\
\hline $\begin{array}{l}\text { Composition of mobile phase } \\
\text { Butanol }( \pm 0.1 \mathrm{ml})\end{array}$ & $100.85,1.4$ & 0.26 & $99.58,1.5$ & 0.70 \\
\hline $\begin{array}{l}\text { Time from chromatography to } \\
\text { derivatization }( \pm 5 \text { min) }\end{array}$ & $101.4,1.05$ & 0.28 & $99.45,0.99$ & 0.72 \\
\hline $\begin{array}{l}\text { Time from derivatization to } \\
\text { scanning }( \pm 5 \text { min })\end{array}$ & $99.67,1.23$ & 0.28 & $99.25,1.05$ & 0.72 \\
\hline Chamber saturation time $( \pm 5 \mathrm{~min})$ & $99.86,0.98$ & 0.28 & $100.14,0.89$ & 0.71 \\
\hline
\end{tabular}

\section{Specificity}

The HPTLC chromatograms were recorded for blank and the formulations under optimized analytical conditions and compared with that of standard, where no additional peaks were observed. The two peaks were completely separated in HPTLC chromatogram, even in the presence of excipients form the sample; no interfering peaks were observed in HPTLC chromatogram. Good correlation was also obtained between standard and sample chromatogram of carbocisteine and amoxicillin. The results of the stress degradation study using acid, alkali hydrolysis, oxidative degradation, show adequate resolution of the degraded product peaks. During selected forced degradation studies the main peaks of both the pure drugs were well resolved from their degraded products confirms the specificity of the method (Fig. 4).Under the optimized chromatographic conditions; degradation products of both analytes were well resolved which was further confirmed by peak purity study (Table 6). Peak purity $\mathrm{r}(\mathrm{s}, \mathrm{m})$ and $\mathrm{r}(\mathrm{s}$, e) values were above 0.99 ; indicating homogeneous peaks. Thus, developed method is demonstrated to be specific.

\section{Solution (Method) stability:}

Stability of solution as described in method development was studied. The solution was assayed after 1, $2,4,6 \mathrm{hr}$. and the results were compared. The $\mathrm{R}_{\mathrm{f}}$ value of 0.28 for carbocisteine and 0.71 for amoxicillin shows no significant difference. The peak area of carbocisteine and amoxicillin were found within the acceptable limit. The\% RSD was found to be less than 2.0 indicating no significant degradation within the indicated period, which was sufficient to complete the analytical process.

\section{Forced degradation study}


Stability-indicating study of carbocisteine and amoxicillin under different stress conditions was carried out as described in procedure section. The main peaks of both the pure drugs were well resolved from their degraded products. Peak purity of analytes peaks for all stress conditions were carried out. A result of this study shows the advantage of mobile phase used to effectively separate the peak of the pure drug from its degradation product. The amount of drug recovered after degradation studies and the $\mathrm{R}_{\mathrm{f}}$ value of degradation products are given in Table 6. The chromatograms obtained after degradation under various conditions are shown in the Fig 4.

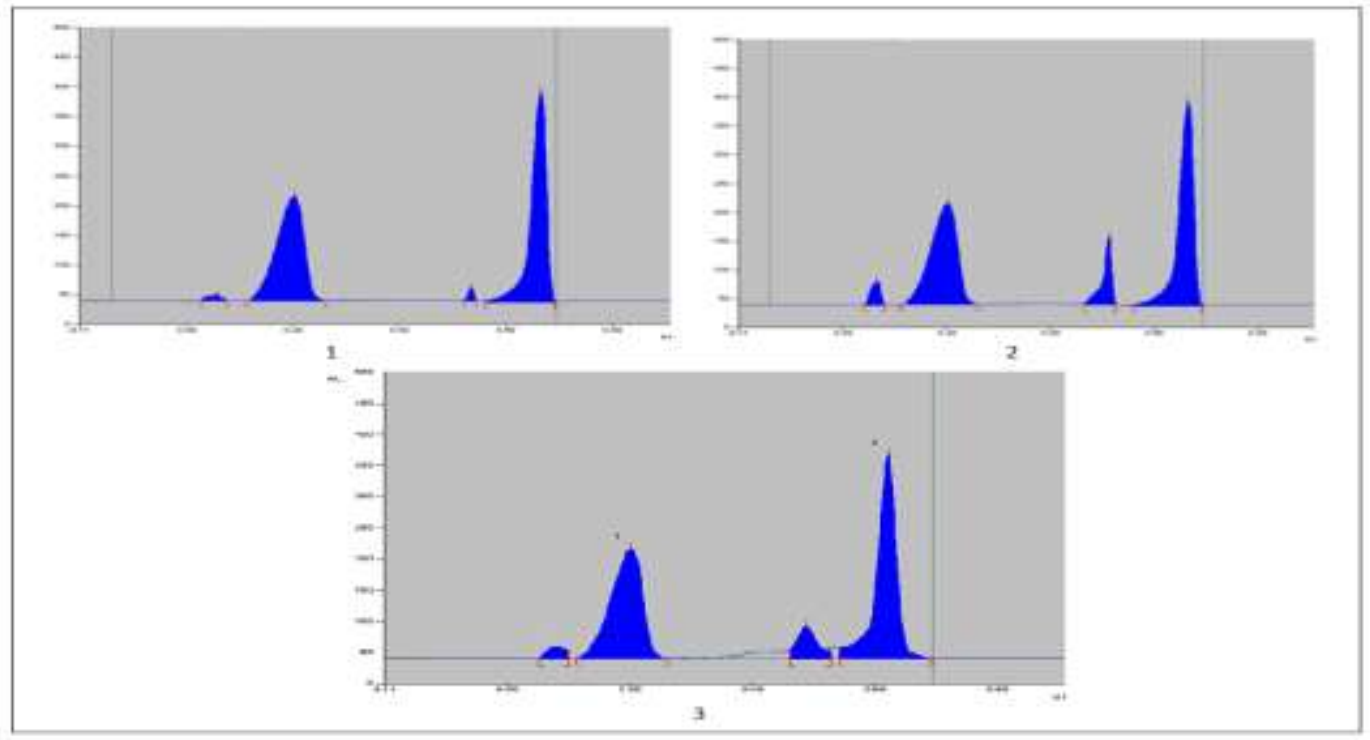

Figure 4: Forced degradation study densitograms for 1) Acid degradation 2) base degradation and 3) hydrogen peroxide degradation.

Table 6: Forced degradation study

\begin{tabular}{|c|c|c|c|c|c|c|}
\hline \multirow{2}{*}{$\begin{array}{l}\text { Analyte and } \\
\text { Stress } \\
\text { Conditions }\end{array}$} & \multicolumn{3}{|c|}{ Carbocisteine } & \multicolumn{3}{|c|}{ Amoxicillin } \\
\hline & $\begin{array}{l}\% \\
\text { Assay }\end{array}$ & $\begin{array}{l}\mathbf{R}_{\mathbf{f}} \text { value of } \\
\text { degradation } \\
\text { products }\end{array}$ & $\begin{array}{l}\text { Peak Purity } \\
\text { r(S,M), } \\
\text { r(M,E) }\end{array}$ & $\begin{array}{l}\% \\
\text { Assay }\end{array}$ & $\begin{array}{l}\mathbf{R}_{\mathrm{f}} \text { value of } \\
\text { degradation } \\
\text { products }\end{array}$ & $\begin{array}{l}\text { Peak Purity } \\
\text { r(S,M), } \\
\text { r(M,E) }\end{array}$ \\
\hline $\begin{array}{l}\text { Acid } 0.1 \mathrm{~N} \mathrm{HCl}, 4 \\
\text { hrs at RT }\end{array}$ & 93.56 & 0.15 & $\begin{array}{l}0.9982 \\
0.9989\end{array}$ & 91.23 & 0.62 & $\begin{array}{l}0.9958 \\
0.9968\end{array}$ \\
\hline $\begin{array}{l}\text { Base } 0.1 \mathrm{~N} \\
\mathrm{NaOH}, 4 \mathrm{hrs} \mathrm{RT}\end{array}$ & 89.43 & 0.16 & $\begin{array}{l}0.9926 \\
0.9986\end{array}$ & 86.62 & 0.58 & $\begin{array}{l}0.9978, \\
0.9991\end{array}$ \\
\hline $\begin{array}{l}\mathrm{H}_{2} \mathrm{O}_{2} 3 \% \text { w/v, } \\
4 \text { hrs R.T }\end{array}$ & 94.62 & 0.17 & $\begin{array}{l}0.9954, \\
0.9979\end{array}$ & 89.84 & 0.57 & $\begin{array}{l}0.9971 \\
0.9984\end{array}$ \\
\hline $\begin{array}{l}\text { Wet } \\
(\text { Thermal)heat } \\
\left.60^{\circ} \mathrm{C}\right), 4 \mathrm{hrs}\end{array}$ & 95.32 & Not detected & $\begin{array}{l}0.9991 \\
0.9989\end{array}$ & 94.63 & Not detected & $\begin{array}{l}0.9979 \\
0.9987\end{array}$ \\
\hline $\begin{array}{l}\text { Dry Heat, } 4.0 \\
\mathrm{hrs}\left(80^{\circ} \mathrm{C}\right)\end{array}$ & 98.45 & Not detected & $\begin{array}{l}0.9983, \\
0.9978\end{array}$ & 97.25 & Not detected & $\begin{array}{l}0.9988, \\
0.9986\end{array}$ \\
\hline
\end{tabular}

\section{Conclusion}

A combination of carbocisteine and amoxicillin is available as a mucolytic drug in the market. As there are no HPTLC reported methods for their simultaneous estimation, high performance thin layer chromatography method was developed and validated for the determination of carbocisteine and amoxicillin. Further to impart stability indicating power to the proposed method, analytes in bulk and formulation were stress degraded by using different commonly applied stress conditions and evaluated for degraded product peak resolution and absence of any coelution in analyte peaks. The standard deviations, \% RSD for the method are 
low, indicating a high degree of precision. The results of the stress studies indicated the specificity of the method. The method gives well resolved peaks of amoxicillin and carbocisteine after exposure to different stress conditions. HPTLC method reduces the duration of analysis and appears to be suitable for routine determination of carbocisteine and amoxicillin compared with the reported methods as well as for stability study of the bulk and formulations. Hence, it can be concluded that the developed HPTLC method is accurate, precise, robust and selective, stability indicating and can be employed successfully in the estimation of amoxicillin and carbocisteine in bulk drug and in pharmaceutical formulation and stability study samples.

\section{Acknowledgements}

The author gratefully acknowledges the Principal and the management of the MCE Society's Allana College of Pharmacy and MAEER'S Maharashtra Institute of Pharmacy, for providing the facility and instruments for the research work. The author also acknowledges Public Testing Laboratory Erandwane, Pune for providing the instrumental facility.

\section{References}

1. Abdulqawi, A. N., Majed, N., Hussein, A., Abdussalam, I. A. T., Abdulhafeed, A., Naser, Z., \& Abdulmoniem, A. (2009). Validation and Application of a Reversed-phase HPLC Method for the determination of Amoxicillin Trihydrate in Human Plasma. Journal of Applied Sciences (Faisalabad), 5(12), 2219-2224.

2. Manzoor, A., Suresh, G., \& Sathish, S. A. (2011). Development and Validation of Amoxicillin by RPHPLC Method in Bulk drug and Pharmaceutical dosage forms. International Journal of Chemtech Research, 3(3), 1037-1041.

3. Prakash, K., Raju, P. N., Kumari, K. S., \& Narasu, M. L. (2008). Spectrophotometric Estimation of AmoxicillinTrihydrate in Bulk and Pharmaceutical Dosage Form. E-Journal of Chemistry, 5(s2), 1114 1116. doi:10.1155/2008/350646.

4. Douša, M., \& Hosmanová, R. (2005). Rapid determination of amoxicillin in premixes by HPLC. Journal of Pharmaceutical and Biomedical Analysis, 37(2), 373-377. doi:10.1016/j.jpba.2004.10.010.

5. Hsu, M. C., \& Hsu, P. W. (1992). High-Performance Liquid Chromatographic Method for Potency Determination of Amoxicillin in Commercial Preparations and for Stability Studies. Antimicrobial Agents and Chemotherapy, 36(6), 1276-1279. doi:10.1128/AAC.36.6.1276.

6. Rele, R. V., \& Patil, S. P. (2010). Reversed Phase High Pressure Liquid Chromatography Technique for Determination of Carbocisteine from Pharmaceutical Formulation. Journal of Chemical and Pharmaceutical Research, 2(4), 24-30.

7. Rele, R. V. (2017). Derivative Spectrophotometric Estimation of Amoxicillin Trihydrate and Carbocisteine by Third Order Derivative Spectroscopy Method in Combined Dosage Form. Journal of Chemical and Pharmaceutical Research, 9(3), 24-28.

8. Dhiraj, S. N., Chandrakant, G. B., Surana, S. J., Venkateshwarlu, G., \& Dekate, P. G. (2009). Development and Validation of RP-HPLC Method for Simultaneous Estimation of Amoxicillintrihydrate and Flucloxacillin sodium in capsule dosage form, International Journal of PharmTech Research, 1(3), 935939.

9. Patel, P., Varshney, V., \& Rohit, M. (2014). Analytical Method Development and Validation For Simultaneous Estimation Of Metronidazole And Amoxicillin In Synthetic Mixture By UV- Visible Spectroscopy. International Journal of Pharmacy and Pharmaceutical Sciences, 6(2), 317-319.

10. Tippa, D. M. R., \& Singh, N. (2010). Development and Validation of Stability Indicating HPLC Method for Simultaneous Estimation of Amoxicillin and Clavulanic Acid in Injection. American Journal of Analytical Chemistry, 1(03), 95-101. doi:10.4236/ajac.2010.13013.

11. Tavakoli, N., Varshosaz, J., Dorkoosh, F., \& Zargarzadeh, M. R. (2007). Development and validation of a simple HPLC method for simultaneous in vitro determination of Amoxicillin and Metronidazole at single 
wavelength. Journal of Pharmaceutical and Biomedical Analysis, 43(1), 325-329. doi:10.1016/j.jpba.2006.06.002.

12. Jayakar, B., Kumudhavalli, M. V., Margret, R. C., Kumar, M., \& Saravanan, C. (2010). Method Development and Validation of RP-HPLC Method for Simultaneous Determination of Amoxicillin and Potassium Clavulanate. International Journal of Pharm Tech Research, 2(1), 906-909.

13. Dhaneshwar, S. R., Dhoka, M. V., \& Chopade, S. S. (2011). Bhusari, Validated HPTLC Method for Simultaneous Estimation of Amoxycillintrihydrate and Ambroxol hydrochloride in Pharmaceutical DosageForm. Asian Journal of Pharmaceutical and Biological Research, 1(2), 129-135.

14. Walash, M. I., Amina, M., Mohamed, E. M., \& Amina, A. A. (2004). Fluorimetric determination of Carbocisteine and Ethionamide in drug Formulation. Acta Chimica Slovenica, 51, 283-291.

15. Walash, M. I., El-Brashy, A. M., E.-S. Metwally, M., \& Abdelal, A. A. (2004). Spectrophotometric determination of penicillamine and carbocisteinebased on formation of metal complexes. IL Farmaco, 59(6), 493-503. doi:10.1016/j.farmac.2003.11.016.

16. Sarode, S. K., Pise, S. T., Dhore, P., Mundhada, D. R., \& Bhaskaran, S. (2013). Development of analytical method for simultaneous estimation of Amoxicillin and Carbocisteine in solid dosage form by RP-HPLC. BioMedRx., 1(4), 360-362.

17. Rele, R. V. (2014). Simultaneous Spectrophotometric Estimation of Amoxicillin and Carbocisteine by Second Order Derivative Spectroscopy Method in combined dosage form. International Journal of Chemical Sciences, 12(4), 1587-1595.

18. ICH. Harmonized Tripartite Guideline, Stability Testing of New Drug Substances and Products (Q1AR2), in: Proceedings of the International Conference on Harmonization, Geneva, February (2003).

19. Bakshi, M., \& Singh, S. (2002). Development of validated stability indicating assay methods — critical review. Journal of Pharmaceutical and Biomedical Analysis, 28(6), 1011-1040. doi:10.1016/S07317085(02)00047-X.

20. ICH. Harmonized Tripartite Guideline, Stability Testing: PhotostabilityTesting of New Drug Substances and Products (Q1B), in: Proceedings of the International Conference on Harmonization, Geneva, November 1996.

21. ICH. Q2 (R1). Validation of Analytical procedures: Text and Methodology International Conference on Harmonization. Geneva, November 2005, pp. 1-13.

22. Sethi, P. D. HPTLC: Quantitative Analysis of Pharmaceutical Formulations. 1sted. New Delhi: CBS Publishers and Distributors., 2013,pp. 15-16.

23. Attimarad, M., Mueen Ahmed, K. K., Aldhubaib, B. E., \& Harsha, S. (2011). High-performance thin layer chromatography: A powerful analytical technique in pharmaceutical drug discovery. Pharmaceutical Methods, 2(2), 71-75. doi:10.4103/2229-4708.84436.

24. Upton, R. T. (2010). Use of High-Performance Thin Layer Chromatography by the American Herbal Pharmacopoeia. Journal of AOAC International, 93(5), 1349-1354.

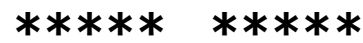

